\title{
Criterios y sentidos de justicia en la dialéctica crociana
}

\section{Criteria and Meanings of Justice in the Croce's Dialectic}

\author{
Angelo ANZALONE \\ Universidad de Córdoba \\ jizanana@uco.es
}

Resumen: El objeto de este trabajo es presentar las principales observaciones de Benedetto Croce sobre el fenómeno jurídico, tema este que siendo parte de su sistema dialéctico ha sido objeto de profundas críticas. Una lectura superficial y ligada solamente a los primeros años de su producción intelectual puede engañar a quien decida acercarse a las complejas dinámicas espirituales de la filosofía. Analizamos, a continuación, si la justicia en Croce se sitúa en el momento económico o moral de la dialéctica del espíritu, supuesto que la dinámica de los distintos momentos de esa dialéctica nos podría hacer pensar que la justicia del fenómeno jurídico es equiparable a la mera satisfacción de intereses individuales. Será necesario comprobar, por tanto, si Croce supera esta concepción que lo ha hecho tan famoso: derecho=economía; filosofía del derecho=filosofía de la economía.

Palabras clave: neoidealismo; espiritualismo; derecho; justicia; economía; ética; religión; historia.
Abstract: To present the great work of Benedetto Croce or summarize it, in its entirety, would be an difficult and complicated task. In this place, and without aim to be exhaustive, We only want to remember some of his main observations on the juridical phenomenon, this is a part of his dialectic system that has been object of deep critics. We believe that a superficial reading and focused only in the first years of his intellectual production can mislead those who want to approach the complex spiritual dynamics of Croce's philosophy; because, certainly, it is possible to find a noble lesson, that is result of an intellectual evolution with a deep sense. We want to know if justice is placed in the economic or moral moment of the Croce's dialectic of the Spirit. More over, the dynamics of the different moments of this dialectic thinking could make us to accept that the justice of the legal phenomenon is comparable with the only satisfaction of individual interests. It will be necessary to verify, therefore, if Croce surpasses or not the conception that has made him so famous: law-economy; philosophy of law-philosophy of economics.

Keywords: neoidealism; spiritualism; law; justice; economy; ethic; religion; history.

\section{Algunas REACCIONES A LA CRISIS DEL POSITIVISMO EN EL SIGLO XIX:}

\section{A MODO DE INTRODUCCIÓN}

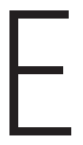
n el último volumen de su «Storia della filosofia del diritto», Guido Fassó recuerda que los principios del positivismo -sin duda alguna la filosofía dominante en la segunda mitad del siglo XIX- empiezan a ser discutidos y negados. Diferentes fueron las reacciones y las direcciones ${ }^{1}$, tratándose de un

1 Para un exhaustivo examen de la crisis del positivismo, con particular referencia al pensamiento filosófico-jurídico contemporáneo, véase FARALLI, C., La Filosofía del Derecho contemporánea, Hispania Libros, Madrid, 2007, con particular referencia a las pp. 9-79. 
fenómeno a encuadrar en la transformación de la sociedad europea de los últimos años del siglo XIX, en la que se discute y se duda de los ideales burgueses de aquel tiempo ${ }^{2}$. En Italia, el predominio del positivismo fue destruido por el neoidealismo, sobre todo por obra de Benedetto Croce (1866-1952) y Giovanni Gentile (1875-1944). Como sabemos, el derecho entendido como actividad del espíritu es seguramente una de las características más peculiares del idealismo y, a tal propósito, se ha llegado a hablar de «negación crociana y gentiliana» de la Filosofía del Derecho, sorprendentemente reducida y disuelta en filosofía de la economía o en la moral ${ }^{3}$.

En este trabajo nos preocuparemos de analizar algunas reflexiones que caracterizan la postura de Croce. En la orientación anti-positivista de la reflexión crociana, la ciencia sirve para medir la realidad, sometida a una filosofía que, en cambio, permite la comprensión y la explicación de lo real. Sobre su polémico pensamiento existe abundante literatura, ya que su actividad historiográfica y bibliográfica es imponente y abarca varios frentes, todos ellos de sumo interés. En las próximas páginas recordaremos cuáles son sus consideraciones acerca del fenómeno jurídico, con el principal objetivo de buscar los criterios y los sentidos del concepto de justicia que él propone (argumento que, en realidad, no ha sido objeto de gran atención por parte de la comunidad científica).

Queremos saber si la justicia, según Croce, se sitúa en el momento económico o moral de la dialéctica del espíritu, ya que la dinámica «de los distintos» nos podría hacer pensar -a simple vista- que la justicia del fenómeno jurídico es equiparable a la mera satisfacción de intereses individuales. Será necesario comprobar, por tanto, si Croce supera esta concepción que lo ha hecho tan famoso (derecho=economía / filosofía del derecho=filosofía de la economía) y, además, será interesante acercar o, en su caso, alejar su posicionamiento de concepciones estrictamente utilitaristas.

\section{EL DERECHO COMO MOMENTO ECONÓMICO DE LA DIALÉCTICA ESPIRITUAL}

Cabe recordar que para Croce el espíritu es uno y es realidad, pero su unidad no excluye distinciones: ante todo entre actividad teórica y práctica; y,

2 En este sentido Fassò, G., Storia della filosofia del diritto, vol. III, Laterza, Bari, 2006, pp. 213 214. En todo caso, el mismo autor observa que algunos entornos, en particular los anticlericales y socialistas, conservaron el positivismo como ascendiente.

3 Ibid., pp. 239 ss. 
ulteriormente, dentro de cada una de ellas, entre actividad del espíritu correspondiente a lo individual o a lo universal. De este modo, la actividad teórica se distingue en conocimiento de lo individual y conocimiento de lo universal (momento estético y momento lógico); mientras que la actividad práctica se distingue en volición de lo individual y volición de lo universal (momento económico y momento ético). El derecho, perteneciente a la esfera práctica, en cuanto actividad volitiva, no encuentra momento de ubicación autónoma: será economía o ética, y Croce no lo cree asimilable al segundo momento sino al primero, en cuanto la voluntad jurídica se dirige hacia la utilidad, esto es, hacia el momento económico del espíritu.

La premisa de la dialéctica crociana, por tanto, es evidente: para el filósofo abrucés todo derecho es abstractamente económico, llegándose, además, a negar el derecho como categoría autónoma y merecedora de estudio 4 . En definitiva, el querer jurídico, o sea aquel querer que pretende alcanzar finalidades jurídicas, es un querer económico, pues se presenta como un querer del individuo, orientado hacia finalidades individuales y nunca universales. Quien obra jurídicamente, según Croce, se mueve empujado por necesidades individuales, que podrán ser a-morales o pre-morales (no necesariamente inmorales ${ }^{5}$ ).

4 Fassò, G., Storia della filosofia del diritto, cit., p. 248. Gentile, en cambio, afirma que el pensamiento en acto es verdad y que la voluntad en acto es moralidad. La ley es un producto de la voluntad y el filósofo siciliano sostiene que lo «querido abstracto originario» (el querer la ley) es custodiado por una voluntad, divina o humana, más fuerte que la nuestra. Fundamental, para entender la dialéctica del teórico del fascismo italiano, es la distinción entre el deseo real, o sea el deseo en acto (ejecutar la ley), y el querer-abstracto (querer la ley). Moral y derecho, basándose en una dialéctica «volente»-«voluto», corresponden a los momentos pensante y pensado, en cuanto el acto del pensar es un acto de voluntad. En la voluntad «volente» encontramos la moralidad que es creadora del bien; en el «voluto», en cambio, que es la objetivizacion del contenido del acto «volente», encontraremos leyes y normas que regulan nuestras conductas, o sea el derecho. La ley, por tanto, es un producto normativo, coactivo e interior al yo. Por esta razón se produce, en la dialéctica del filósofo siciliano, una identificación de la voluntad del individuo y de la voluntad del Estado en la unidad del sujeto absoluto. Sobre la unidad de las categorías teórica y práctica, el autor se expresa en GENTILE, G., Genesi e struttura della societá: saggio di filosofia pratica, Sansoni, Firenze, 1946, pp. 7-10. Sobre las relaciones entre los conceptos de derecho, estado y moralidad, en cambio, en las pp. 57-70. El pensamiento gentiliano, sustancialmente, no diverge mucho, en cuanto a resultados, del de Croce, pues ambos niegan el derecho como categoría autónoma y merecedora de estudio: para el abrucés, como decíamos, todo derecho es abstractamente económico; para el siciliano, en cambio, todo derecho es abstractamente ético. Cfr. Fassò, G., Storia della filosofia del diritto, cit., p. 248.

5 Battaglia, F., Curso de filosofía del derecho, vol. II, traducción de la tercera edición italiana por Francisco Elías de Tejada y Pablo Lucas Verdú, Instituto Editorial Reus, Madrid, 1951, pp. 36-38. 
Ciertamente provocador es el título de su memoria «Riduzione della filosofía del diritto alla filosofia dell'economia», presentada en Nápoles en $1907^{6}$. En ella se plantea la cuestión de la naturaleza del derecho pues, a su entender, el único problema que debería interesarle a la Filosofía del Derecho es, precisamente, el dilema relativo a la naturaleza del derecho mismo. Al efecto, Croce excluye expresamente algunos planteamientos típicos que considera insuficientes y poco útiles para la investigación filosófica acerca del derecho. En primer lugar, el método historicista -en su opinión- es reduccionista pues circunscribe el problema a una mera historia universal del derecho o de la fenomenología jurídica; en segundo lugar -sigue el autor- el método empírico, movido por el afán de elaborar una teoría general del derecho, se encierra en el mundo de los pseudoconceptos empíricos o abstractos; en tercer lugar, el método iusnaturalista -a su juicio- insiste demasiado en las pretensiones del antiguo derecho natural, auspiciando una legislación perfecta para el género humano o un código ideal y eterno que negaría el papel activo de la historia ${ }^{7}$.

¿Cuál es, por tanto, la naturaleza del derecho? ¿Cuál es su fundamento? Es aquí donde la dialéctica de los distintos se reafirma, pues Croce desea unificar el derecho y su fundamento en la categoría de lo útil ${ }^{8}$.

De gran importancia son sus consiguientes consideraciones sobre el concepto de ley, ya que Croce niega la identificación entre derecho y ley. Las leyes, en el derecho, serían meras abstracciones, es decir, un conjunto de normas representadas como pseudoconceptos, generalizaciones o esquemas abstractos. A pesar de su gran utilidad, en cuanto capaz de orientar las conductas humanas en una dirección común, la ley se presenta como un conjunto de acciones posibles en abstracto. En este sentido, el querer intrínseco de la ley constituye una abstracción, pues un querer abstracto equivale a querer abstractamente. En cambio, el momento concreto del querer consiste en la decisión última y final del querer mismo, que radica en adecuar, o no, la conducta individual al contenido abstracto de la ley. En definitiva, adquiere mucha importancia el momento de la ejecución de la ley, es decir, el acto individual «sub lege», ya

6 Croce, B., Riduzione della filosofia del diritto alla filosofia dell'economia, Ricciardi, Napoli, 1926.

7 En cuarto y último lugar -concluye Croce- el método precettistico (termino que no queremos traducir por no desvirtuar su sentido originario) no quiere renunciar a la función práctica de la filosofía del derecho, que consistiría en asignar fines últimos a los preceptos jurídicos, llegando incluso a inventar cualquier finalidad para asignar una función practica a la investigación filosófica del fenómeno jurídico. Ibid., pp. 7 y 8.

8 En este sentido concluye, por ejemplo, Mustè, M., «Benedetto Croce e il problema del diritto», Novecento, 4 (1992), pp. 62 y 63. 
que se trata de un acto que se manifiesta como económico. Se nos presenta, nuevamente, el derecho diluido en la economía?.

Ya sabemos, por tanto, que el derecho -para Croce- es un fenómeno practico que encuentra su fundamento en lo útil, esto es en el momento económico de la dialéctica espiritual; la ley, por otra parte, es un instrumento de la voluntad que, para hacerse concreto, necesita que la acción individual sea conforme al precepto normativo. Podríamos decir, por tanto, que la ley pensada es una mera abstracción y que la ley concreta será aquella que se realiza ejecutándola. Nos preguntamos, a la luz de estas consideraciones, si el derecho, a-moral (y no necesariamente inmoral, como diría el filósofo italiano) y fundamentado en lo útil, es un fenómeno que permite la creación de instrumentos económicos-jurídicos (las leyes) al servicio de una moral universal (o de la idea de justicia). O si, por el contrario, con la proclamada búsqueda de lo útil, cada individuo persigue fines morales egoístas, conductas que, en todo caso, se encontrarían amparadas por las leyes. Dicho de otro modo, ¿es Croce un utilitarista? Su reducción dialéctica del derecho a la economía, y de la filosofía del derecho a filosofía de la economía, ¿implica una visión del derecho como mero conjunto de instrumentos al servicio de finalidades morales individuales o universales? ¿Es el derecho un fenómeno útil para asegurar un mínimo ético? Se plantea así la polémica cuestión que inquieta toda postura filosófico-jurídica, es decir, la delicada relación entre derecho y moral.

\section{LA DOBLE APARIENCIA DE LA ACTIVIDAD JURÍDICA.}

De las acusaciones de utilitarista, Benedetto Croce tuvo que defenderse pocos años después de haber publicado su Riduzione della filosofia del diritto alla filosofia dell'economia. En 1914 escribía:

$\ll D a$ quando, or sono circa otto anni, lessi all'Accademia Pontaniana la mia memoria sulla Riduzione della filosofia del diritto alla filosofia dell'economia, e feci cadere quella grossa pietra sul formicaio dei compilatori d'Istituzioni di filosofia del diritto [...], sto a guardare il curioso rimescolio e viavai che n'è nato e che non cessa, anzi si agita sempre più sconvolto e vivace. Tutti girano e rigirano intorno a quella mia memoria, anche coloro che la sentenziano paradossale, assurda, sofistica, retrograda, sbagliata da cima a fondo» ${ }^{10}$.

9 En esto términos se expresa BatTaglia, F., Curso de filosofía del derecho, cit., pp. 37-38.

10 Croce, B., «Intorno alla mia teoria del diritto», La Critica. Rivista di Letteratura, Storia e Filosofia, 12 (1914), p. 445. 
Pero con anterioridad a la citada reflexión, en realidad, y solo un año después de haber leído aquella polémica memoria, el filósofo italiano quiso insistir en su intención de «rehabilitación» de la moral, advirtiendo que trataba de presentar una teoría a-moral (y no inmoral) del derecho, sostenida por una visión rigidísima de la moral misma, una moral que, actuando en concreto, pliega su instrumento a la actividad jurídico-económica ${ }^{11}$. Como podemos apreciar a continuación, son notables las afirmaciones con las que Croce abre sus «Obiezioni alla mia tesi sulla natura del diritto».

En primer lugar, el abrucés considera que no se le puede atribuir una concepción materialista del derecho, ya que, en su dialéctica, la actividad económica, en la que luego se resuelve el derecho, es idealista. Por esta razón, observa que las leyes jurídicas se diferencian de las leyes económicas tal y como el hecho práctico se diferencia de su teoría (y no como un hecho práctico se diferencia de otro hecho práctico) ${ }^{12}$. Por otra parte, confuta la tesis según la cual la economía es cosa del hombre aislado mientras que el derecho es actividad del hombre asociado. Concretamente, Croce sostiene que el individuo aislado es siempre un individuo asociado, ya que vive en la naturaleza y en ella o con ella da lugar a una sociedad. Tanto aislada como colectivamente considerado, el individuo se dota de normas y reglas a seguir para satisfacer sus necesidades y resolver sus problemas: el hombre económico, pues, mira a los demás hombres, animales o cosas como un conjunto de condiciones, útiles o menos útiles, para su obrar ${ }^{13}$.

El hombre jurídico, en cambio, considera a los demás como personas, reconociéndose en ellos. Esta relación, en la que todos se reconocen mutuamente no como meros individuos sino como personas, deja de ser puramente jurídica y comienza a contaminarse de contenidos éticos. Si se desea calificar dicha relación como jurídica, observa Croce, habrá que admitir que derecho y moral coinciden, sin crearse ulteriores problemas acerca de sus diferencias. En realidad, sigue el autor, existe una diferencia, ya que, por ejemplo, jurídicamente hablando, asalariado y esclavo son lo mismo, mientras que no lo son desde la perspectiva ética ${ }^{14}$.

11 Así lo ha visto también Mustè, M., «Benedetto Croce...», cit., p. 68. Véase Croce, B., «Obiezioni alla mia tesi sulla natura del diritto», La Critica. Rivista di Letteratura, Storia e Filosofia, 6 (1908), p. 150.

12 Ibidem.

13 Ibid., pp. 151 y 152.

14 Ibid., p. 152. 
A la luz de estas consideraciones, por tanto, ¿qué es, definitivamente, la actividad jurídica? Comprar algo, donar algo, herir físicamente a alguien... son acciones que, según Croce, se caracterizan por ser propiamente económicas, o de conveniencia y que sin duda alguna tendrán trascendencia jurídica. Cosa diferente, es la actividad de fabricación de las leyes, considerada por el italiano como un hecho mucho más complejo ya que necesita un trabajo previo de abstracción teórica y, luego, un acto práctico mediante el cual se sanciona que las acciones de los individuos deben adaptarse al esquema dibujado por ese modelo abstracto ${ }^{15}$. Como podemos comprobar la actividad jurídica -según Croce- se compone de dos momentos fundamentales, distintos e íntimamente relacionados, individual uno y universal el otro, económico el primero y, nos preguntamos, ¿ético el segundo? Respondiendo positivamente a esta pregunta, sin ulteriores especificaciones, Croce no haría otra cosa que compartir las observaciones de Gentile; pero sabemos que la mayor crítica que el abrucés dirige al siciliano es precisamente la de haber identificado incorrectamente y disuelto el derecho en la moral ${ }^{16}$. Para Croce, en esta fase de su pensamiento, la actividad jurídica participa de estos dos momentos, individual y universal (o colectivo), concreto y abstracto. Derecho y moral, para él, son dos formas distintas de actividad espiritual, siendo la ley una producción compleja en la que participan varias actividades.

Para distinguir entre derecho y moral, según Croce, hay que aceptar esa doble naturaleza o apariencia de la actividad jurídica. En este sentido, el derecho se manifestaría en dos formas: la primaria y simple, del hecho individual; la secundaria y compleja, de la ley. Ahora bien, la creación de leyes, o mejor dicho de normas, es una actividad no exclusiva del derecho, sino también de la moral o de la religión. Y en las tres actividades participan elementos económicos, ya que, para conseguir, incluso, fines morales o religiosos (además de jurídicos) será necesario manejar herramientas útiles para dirigir o redirigir la actividad individual ${ }^{17}$.

Croce concluye afirmando que para refutar su tesis acerca del derecho, habría que demostrar que en la actividad práctica puede distinguirse, además de entre actividad de lo individual y de lo universal, en algo más, en un híbrido

15 Ibid., pp. 152 y 153.

16 Nos hemos referido a la dialéctica gentiliana en la nota 4.

17 Ibid., p. 153. 
entre individual y universal, en un tertium quid. Mientras no se demuestre la existencia de esa tercera categoría su tesis será inatacable, pues la actividad jurídica, siendo práctica, o es económica o es ética. Como no es solo ética, solo queda una opción hasta que se demuestre lo contrario ${ }^{18}$.

\section{El desafío dialéctico de CRoce: La búsqueda de UN TERTIUM QUiD ENTRE LO INDIVIDUAL Y LO UNIVERSAL}

Cabe apreciar cómo el proceso jurídico descrito por Croce se mueve según una dialéctica que se articula perennemente entre lo «universal» y lo «individual», pues habla de una legalidad abstracta contrapuesta, distinta y compensada por un momento práctico-concreto de la vida. Se trata, a nuestro parecer, de una posición flexible ya que, en primer lugar, no es posible negar que el derecho presenta ciertas notas de abstracción; pero ese contenido (abstracto) entra en yuxtaposición con aquel querer volitivo «sub legem» (como lo llamaría Croce). Se nos presenta así un concepto de derecho impregnado de momentos universales e individuales al mismo tiempo. Por esta razón, pensamos que la especulación crociana nos hace ver cómo en el derecho viven dos momentos, uno volitivo con vocación universal y el otro, también volitivo pero con vocación individual. Además, dicha yuxtaposición entre abstracción y concreción, momentos distintos y no opuestos permite comprender cómo Croce descubre el binomio de fundamental importancia en el derecho, es decir, la doble apariencia del fenómeno jurídico entre el pensar y el querer. El derecho, abstractamente entendido, es actividad del pensamiento que precede a la acción y que, de este modo, planea las acciones posibles: esta es la doble naturaleza del derecho.

¿Existe, por tanto, esa categoría intermedia, ese tertium quid capaz de refutar la tesis del filósofo italiano? Nosotros creemos que su existencia es fácilmente demostrable y que, además, el mismo Croce la trata y la admite (quizás sin darse cuenta) en su especulación. Al efecto, recordamos que su posición se alinea claramente contra aquellas tendencias del pensamiento jurídico que consideran la legalidad como perteneciente exclusivamente al momento teórico, entendiendo así las leyes y las normas como simples proposiciones lógi-

18 Ibid., pp. 154 y 155. 
cas. Del mismo modo, su posición se opone a las tendencias que conciben las normas como meros mandatos imperativos. En el primer caso, según Croce, la investigación se limita al momento cognoscitivo sin tener en cuenta que éste constituye la premisa del siguiente momento, igualmente necesario (el práctico). En el segundo, en cambio, la limitación especulativa consiste en la mera individuación de algunos matices del momento práctico (conjunto de imperativos y de mandatos) sin ascender a lo que ha engendrado y da coherencia a ese momento. Ambas tendencias son rechazadas por Croce, ya que en ambos casos se trata de una abstracción cerrada de todos los conceptos a través de un esfuerzo de inducción y generalización. El derecho, para él, es una actividad práctica que sirve, en última instancia, para la satisfacción de intereses individuales.

Subrayamos la incidental «en última instancia» ya que Croce se refuta a sí mismo cuando admite la existencia de otro momento, previo y necesario, identificable con la actividad de crear las leyes y/o las normas, actividad -dice él mismo autor- típica de otros fenómenos de la actividad humana, como, por ejemplo, la moral o la religión. Es decir, la actividad jurídica, desde una perspectiva económica, es un conjunto de herramientas a disposición de los individuos; desde la perspectiva ética, en cambio, se presenta como un conjunto de instrumentos al servicio de la moral para que esta pueda reivindicar sus contenidos más básicos. O sea, la actividad jurídica es práctica, pero no exclusivamente económica o exclusivamente ética: sirve a la moral para que ésta reivindique sus contenidos y, después, y económicamente hablando, servirá a los individuos en la satisfacción de sus intereses.

Acabamos de encontrar y descubrir, sin grandes dificultades, ese tertium quid, entre lo universal y lo individual, que caracteriza la actividad jurídica y que el mismo Croce expone implícitamente en su dialéctica. Que en la actividad de creación de normas y en la actividad de ejecución o incumplimiento de las mismas, participen siempre instancias económicas, sigue siendo algo presente en la postura crociana. Esto no quiere decir que su planteamiento sea del todo asimilable a tendencias utilitaristas o que el derecho quede condenado a no vivir autónomamente en la dialéctica de los distintos. Tanto es así que Croce se ve obligado a refutar, como hemos visto anteriormente, todas las objeciones formuladas hacia su teoría, hasta el punto de concebir, entre universal e individual, un concepto de derecho y una idea de actividad jurídica mucho más completa, rica y compleja de lo que una reflexión poco atenta de su dialéctica puede hacernos imaginar. 


\section{LA REIVINDICACIÓN DE LO ÚTIL PERMITE LA REHABILITACIÓN}

DE LA MORAL

Del año 1916 es un texto que asume un importante significado en la evolución especulativa de Croce. Nos referimos a «La redenzione di un concetto condannato» ${ }^{19}$, un escrito que, como ha sido ya señalado ${ }^{20}$, sirve para comprender las intenciones anti-utilitaristas del iusfilósofo.

En primer lugar, cabe señalar que Croce, con el citado manuscrito, desea otorgar dignidad al concepto de lo útil, categoría que para él no merece ser tratada con diferente dignidad respecto a las categorías de lo verdadero, de lo bueno y de lo bello. Es decir, que para evitar que lo útil se convierta en «hijo de nadie», o en un «don nadie», y para evitar que desate su consecuente aptitud maligna hacia las demás categorías, será fundamental -según el italiano- devolverle su espacio autónomo junto a las tres categorías anteriormente citadas. Lo útil injustamente tratado, dice Croce, se vengará como un ser impertinente y maligno, robando espacio en los tratados de ética o buscándose malos amos, los llamados utilitaristas, quienes le permitirán «casarse salvajemente» con la ética. Por esta razón, algunos filósofos hayan tenido que pelear, en el plano especulativo, para rescatar a su amada hija (la ética), torpemente raptada por lo útil con la complicidad de sus amos ${ }^{21}$.

La solución propuesta por Croce es la siguiente: asignar a cada cual su sitio y acabar así con la tridimensionalidad (lo verdadero, lo bueno y lo bello) de los términos espirituales. Esto será posible introduciendo un cuarto término y sosteniendo, sin grandes complicaciones y con el único objetivo de evitar estériles peleas filosóficas y nocivas actitudes espirituales, una realidad espiritual de tipo cuadrimensional. Dicha propuesta, según Croce, no ha sido entendida en su profundidad por toda la comunidad intelectual, pues una parte de ella le acusa de utilitarista, cualidad que él no acepta y que además desea renovar para superarla. Cuando dos partes discuten y disputan para obtener algo, la mejor solución consiste -afirma Croce- en reconocer a cada parte lo que le toca, obligándole a dejar de desear lo que no le pertenece. Lo mismo hay que hacer con el utilitarismo -prosigue el autor- pues a este no le pertenece la moral sino solamente el concepto de útil ${ }^{22}$.

19 Croce, B., «La redenzione di un concetto condannato», La Critica. Rivista di Letteratura, Storia e Filosofia, 14 (1916), pp. 477-483.

20 Cfr. Mustè, M., «Benedetto Croce...», cit., p. 68, nota 18.

21 Cfr. Croce, B., «La redenzione di un concetto...», cit., p. 477.

22 Ibid., p. 478. 
Todas estas consideraciones tienen el objetivo de reivindicar un espacio autónomo de acción para lo útil y, consecuentemente, de no consentir que lo útil se apodere de los oficios éticos. Nosotros pensamos que se trata de la coherencia del método que mueve la dialéctica de los distintos crociana, pues en ella encontraremos lo útil entendido como pura fuerza y como energía de la voluntad humana que está separada -según Croce- de la energía de la idealidad moral, así como de la realidad de la justicia. Todo pensador -según el filósofo abrucés- debería así entender que este método es el único capaz de salvar y rescatar la justicia de la impotente abstracción (mera idealidad), liberándola al mismo tiempo de la potente concreción (mera utilidad). Es fundamental convalidar la justicia y no permitir que otras categorías, aparentemente amigas, puedan invalidarla. Así será posible distinguir, sobre todo en el mundo práctico, lo útil del bien, tal y como se distingue el bien de la verdad. Esto no quiere decir que cualquier mala acción pueda justificarse afirmando que ha sido realizada bajo el impulso de la utilidad y no de la bondad, pues tal afirmación demuestra, en quien la mantiene, el mezquino intento de callar el reproche de los demás y el remordimiento en sí mismo ${ }^{23}$.

Es preciso recordar que el concepto de lo útil (o de lo económico) es el centro de gravedad de la «Filosofia della pratica. Economica ed etica», obra que se presenta, sustancialmente, como el tercer volumen de los cuatro que componen la «Filosofia dello spirito» de Benedetto Croce ${ }^{24}$. La economía, para el italiano, es una forma del espíritu, una de las cuatro formas que componen su sistema (estética, lógica, economía y ética), y, evidentemente, no es la economía de los economistas, sino el conjunto de acontecimientos de la vida fáctica que solemos definir económicos, como lo serían la política o el derecho. En este sentido, la actividad económica persigue fines individuales ya que con ella se desea obtener lo que corresponde a las condiciones de hecho en las que el individuo se encuentra; la actividad ética, en cambio, realiza fines universales ya que el querer de dicha actividad, a pesar de estar vinculado a aquellas condiciones de hecho en las que el individuo se encuentra, se refiere también a algo que le trasciende ${ }^{25}$.

Debido a que -según Croce- no existen acciones desinteresadas desde el punto de vista económico, pero sí pueden darse acciones a-morales, el mo-

\footnotetext{
23 Ibid., pp. 478 y 479.

24 Nos referimos a Croce, B., Filosofia della pratica. Economia ed etica, Laterza, Bari. 1950, pp. $201-$ 236.

25 Ibid., p. 203.
} 
mento ético siempre se verá teñido por instancias económicas. Dicho de otro modo, el abrucés sostiene una relación de doble grado entre las dos formas de la actividad práctica, económica y ética, según la cual el grado económico es independiente del grado ético, mientras que este último no puede pensarse sin el primero ya que siempre se encontrarán en él acciones efectivamente útiles. Por tanto, la acción ética siempre será una acción ético-útil ${ }^{26}$, pues en ella encontraremos siempre un fin individual a pesar del horizonte de trascendencia que le proporciona su universalidad. Una acción ética siempre será útil, sin querer esto decir que sea ética por ser útil.

Con estas observaciones, Croce desea rechazar la idea del utilitarismo, o sea la negación de la forma ética. Del mismo modo, desea rechazar una idea meramente abstracta de la moral (astrattismo morale, queriendo utilizar sus pa$\operatorname{labras}^{27}$ ). El suyo quiere ser un punto intermedio, una dialéctica de doble grado perfectamente simétrica respecto a la que establece entre las dos formas de la actividad teórica (la estética y la lógica). Por esto dirá que ese doble grado, estético y lógico, de la actividad teórica, tiene importantes consecuencias en la actividad práctica ya que ésta también se divide en un primer y un segundo grado, donde el primero implica al segundo. El primer grado práctico es la actividad meramente útil o económica; el segundo es la actividad moral. La economía, pues, es como la estética de la vida práctica; la moral es como la lógica $^{28}$. Querer económicamente equivale a querer un fin; querer moralmente equivale a querer un fin racional -sostiene Croce-. Esto significa que quien quiere y obra moralmente no puede no querer y obrar útilmente, pues ¿cómo podríamos querer el fin racional sin quererlo junto con su fin particular? No obstante, lo contrario no es verdadero. Tampoco en la estética el hecho expresivo debe tener un vínculo necesario con el hecho lógico. Es decir, se puede querer económicamente sin querer moralmente, pudiéndose, en cambio, realizar un conjunto de acciones económicas impulsadas por fines objetivamente irracionales (inmorales) ${ }^{29}$.

Hasta aquí, pues, el intento crociano de rehabilitación de la moral como consecuencia de la reivindicación de un espacio autónomo para la categoría de lo útil. El descubrimiento de lo útil, al puro estilo crociano, representa una

26 Ibid., p. 228.

27 Ibid., p. 219.

28 Cfr. Croce, B., Estetica como scienza dell'espressione e linguistica generale, Laterza, Bari, 1965, p. 61.

29 Cfr. Croce, B., Tesi fondamentali di un'estetica come scienza dell'espressione e linguistica generale, reimpresión de la edición del 1900, cuidada por F. Audisio, Bibliopolis, Napoli, 2002, p. 46. 
de las novedades más radicales de su filosofía ${ }^{30}$. Una categoría que se presenta inquieta en su estructura, oscilante entre la capacidad de construir esquemas o conceptos prácticos y la destructiva energía vital que dicha capacidad esconde en cuanto vinculada a los imperativos del placer y del dolor ${ }^{31}$.

\section{LA LEGALIDAD COMO ESQUEMA LÓGICO-NORMATIVO}

\section{DE LAS ACCIONES POSIBLES}

Hemos comprobado que Croce atribuye mucha importancia a la volición de lo individual (que será la economía); esto probablemente se debe a que el italiano mantiene un fuerte sentido económico de la realidad, así como de los estímulos que regulan la vida humana. En este escenario, decíamos, el derecho se presenta, ante todo, a-moral, en el sentido de que sus objetivos no coinciden con los que son propios de la moral. Pese a su utilidad la ley se presenta como un conjunto de acciones posibles en abstracto. Aunque irreal, pues el querer intrínseco de la ley constituye una abstracción y un querer abstracto equivale a querer abstractamente, la ley encuentra su realidad en su ejecución material, o sea en el acto individual «sub lege», momento verdaderamente práctico y concreto. Croce considera que la ley representa una ayuda para la volición real ${ }^{32}$, tal y como, en la esfera teórica, los géneros literarios pueden ayudar a favorecer la creación intuitiva ${ }^{33}$, ya que para querer y ejecutar un acto individual es oportuno guiarse por lo genérico, momento más amplio y del cual, aquel acto, es caso singular: es buena cosa, por tanto, atender a las clases de acciones de las que el acto individual es componente ${ }^{34}$.

En la dialéctica de los distintos, por tanto, se admiten implicaciones necesarias entre sus distintos momentos. Es la categoría del derecho la que nos

30 Cfr. D'Angelo, P., «Estetica ed economia in Croce», en P. D’Angelo, E. Franzini, G. Lombardo, S. Tedesco (a cura di), Costellazioni Estetiche, Edizioni Angelo Guerini e Associati, Milano, 2013, pp. 98-103.

31 Cfr. Muste, Marcello, «Filosofia della pratica», <http://www.treccani.it/enciclopedia/filosofia-della-pratica_\%28Croce-e-Gentile\%29/>, 2016 (16 de mayo de 2017), párrafo «Il male e le passioni».

32 Croce, B., Filosofia della pratica. Economia ed etica, cit., p. 334.

33 Cfr. Mustè, M., «Filosofia della pratica», cit., párrafo «Economia ed etica».

34 La ayuda de la ley, para el buen funcionamiento de la vida en sociedad, es comparable, según Croce, a la ayuda de los andamios para construir una casa. Croce, B., Filosofia della pratica. Economia ed etica, cit., p. 334. 
permite comprender el funcionamiento de dichas implicaciones, ya que hemos podido comprobar que el derecho - para Croce- es un fenómeno práctico que encuentra su fundamento en lo útil, esto es en el momento económico de la dialéctica espiritual; la ley, por otra parte, es un instrumento del querer que, para hacerse concreto, necesita que la acción individual se conforme al precepto normativo. Podríamos decir, por tanto, que la ley pensada es una mera abstracción y que la ley concreta será aquella que se hace ejecutándola. $\mathrm{Al}$ principio de este trabajo nos preguntábamos si el derecho, a-moral (y no necesariamente inmoral, como diría el filósofo italiano) y vinculado a lo útil, es un fenómeno que permite la creación de instrumentos económicos-jurídicos (las leyes) al servicio de una moral universalmente entendida. $\mathrm{O}$ si, por el contrario, con la proclamada búsqueda de lo útil, se afirma que cada individuo persigue fines morales individuales bajo el amparo de las leyes jurídicas.

Hemos presentado, siguiendo las observaciones crocianas, la legalidad como el momento abstracto en el curso del proceso práctico, capaz de asegurar una coherencia a la acción, adelantándola, organizándola y predisponiéndola. Cumpliendo dichas funciones, el orden legal consigue organizar la sociedad, en el sentido de que la legalidad es aquel esquema lógico-normativo de las acciones posibles: lógico ya que recoge y dibuja las acciones en una clase común; normativo ya que quiere disciplinarlas mediante normas expresas y reconocidas en la estructura social. He aquí los dos momentos fundamentales, inicial y final, del derecho abstracto (legalidad): capacidad de asegurar las condiciones de vida de la sociedad en una determinada estructura y capacidad de orientar y evitar que la acción caiga en el capricho. Y esto, evidentemente, debido a que no puede sostenerse que la conciencia y el pensamiento, entendidos como momentos internos de la acción, sean indiferentes para el derecho que, en realidad, contempla la acción en su complejidad, en todos sus momentos, siendo vanos los intentos de disociar sus articulaciones internas de las externas.

Nosotros consideramos que la juridicidad se encarna siempre en el «deber-ser» como criterio ideal que proclama un valor, encontrándolo y ubicándolo en la esfera deontológica o ética. Ese criterio, expresado por el derecho e intrínseco de valor, puede ser calificado como «supraexistencial», ya que vive en un plan supraordenado al hecho concreto. Mediante ese criterio será posible discriminar las acciones justas de las injustas, aclarando, en la juridicidad, lo que merece consideración jurídica o no. En efecto, no hay discusión acerca del derecho que no esté acompañada de una mínima referencia a la justicia. El nexo no puede ser roto o puesto fácilmente en duda, siendo discutibles aquellas posturas intelectuales que mantienen una neta separación entre los 
dos términos. Croce, realmente, no separa las dos categorías para proclamar la ausencia de enlace entre ellas, sino para tratar con coherencia dialéctica cada momento del espíritu. Hemos visto, efectivamente, que la reivindicación de lo útil le sirve al abrucés para rehabilitar la existencia, en el espíritu, de un auténtico momento moral.

Por otra parte, y como consecuencia, también hemos podido ver como Croce defiende la pureza de la esfera jurídica: ésta no encuentra sus bases en un principio moral ni inmoral, sino a-moral; un principio de pura conveniencia económica que no permite la participación de la conciencia moral ni del remordimiento. $\mathrm{Y}$ esto Croce nos lo transmite cuando publica «La giustizia come concetto giuridico», siéndole suficiente citar algunos fragmentos del interrogatorio al famoso ladrón, asesino y poeta francés Pierre François Lacenaire (ejecutado en París en 1836), considerando agudas y acertadas sus afirmaciones ${ }^{35}$ :

-Acusado: «Ma tête était mon enjeu. Fe n'ai pas compté sur l'impunité; il y a une chose, en effet, à laquelle on este forcé de croire; c'est la justice, parce que la société se fonde sur l'ordre». -Magistrado: «Mais ce sentiment de la justice c'est la conscience». -Acusado: $\ll$ Moins le remords» ${ }^{36}$.

\section{LA CONSIDERACIÓN DEL PRINCIPIO ÉTICO}

A la luz de todas estas observaciones, ¿̇uál es la consideración de Croce sobre el principio ético que preside la actividad jurídica? ¿El derecho solo encuentra vida autónoma en lo útil? Ciertamente no, ya que afirmarlo equivaldría a conocer solo parcialmente la postura crociana, ignorando su complejidad y evolución. Decíamos que Croce se refuta a sí mismo al admitir la existencia de un momento, previo y necesario, identificable con la actividad de crear las leyes y/o las normas. La actividad jurídica, desde una perspectiva económica, es un conjunto de herramientas a disposición de los individuos; desde la

35 Croce, B., «La giustizia come concetto giuridico», en Discorsi di varia filosofia, vol. II, Bibliopolis, Napoli, 2011, pp. 559-560.

36 Acusado: «Mi cabeza era mi apuesta. Yo no esperaba la impunidad; hay una cosa, en efecto, en la cual se debe necesariamente creer; esta es la justicia, puesto que la sociedad se funda en el orden». Magistrado: «Pero ese sentimiento de justicia es la conciencia». Acusado: «Menos el remordimiento». La traducción es nuestra. Apud Croce, B., La giustizia come concetto giuridico, cit., p. 560. 
perspectiva ética, en cambio, es un conjunto de instrumentos al servicio de la moral. En resumidas cuentas, la actividad jurídica es práctica y no exclusivamente económica o ética, esto es, sirve a la moral para que ésta reivindique sus contenidos y, después, económicamente hablando, servirá a los individuos en la búsqueda de sus intereses. Hablábamos, más arriba, de ese tertium quid, entre lo universal y lo individual, que caracteriza la actividad jurídica y que el mismo Croce expone implícitamente en su dialéctica.

Por esta razón, se ha observado que la reducción del derecho a lo útil, en realidad, y al menos en las intenciones crocianas verdaderas, podría ser la solución a las disputas entre utilitarismo e iusnaturalismo (de corte racionalista, añadiríamos nosotros), ya que ambas orientaciones doctrinales se presentan unilaterales y desconocedoras de la complejidad de la realidad práctica, en la que participan los momentos universales e individuales al mismo tiempo. Por un lado, la exigencia de una autonomía del momento individual se ubica y encuentra su espacio en la esfera económica, por otro lado, la exigencia de lo ideal y de lo universal encuentra satisfacción en el superior ámbito moral. La voluntad, en toda su extensión, o sea, universal en el momento creador de las normas e individual en el momento de ejecución de las mismas, es el nexo que vincula a las dos categorías ${ }^{37}$.

En otro orden de cosas, se ha afirmado que la volición práctica de la moral, concebida, en la dialéctica crociana, como la expresión de la volición universal, no presenta una ética natural o una ética formal, ni tampoco contenidos eternos; porque la ética -para Croce- es la actuación del espíritu que manifiesta, de modo racional, actos y comportamientos particulares en una meta de perenne mejoría humana ${ }^{38}$. En realidad, nosotros entendemos que el

37 Hemos utilizado aquí algunas de las observaciones de Mustè, M., «Benedetto Croce...», cit., pp. 72 y 73 . Es preciso reconocer que, en la parte final de este trabajo, el autor señala que la postura de Croce deja abierta la puerta a una serie de incontrolados dualismos. Por ejemplo, entre «derecho»y «derechos» o «derecho»y «política»; en este último caso, según Mustè, si el derecho es una categoría espiritual y si la política se manifiesta dentro de la dimensión económica, tendríamos una concepción de la categoría política sometida a la mera ley de la fuerza, o sea de lo útil, perdiéndose así todo tipo de relación con el derecho o con la moral. Este punto abierto e incontrolado de la postura jurídica crociana, en el que faltan, afirma Mustè, los contactos entre el «derecho»y el «estado de derecho», es la probable causa de la faceta iliberal de Croce que tantas veces han señalado sus intérpretes.

38 En este sentido remitimos a la interpretación de la dialéctica crociana realizada en «Il pensiero filosofico di Benedetto Croce», en Bimestrale della Biblioteca Giovanni Spadolini, n. 9 (Nuova Serie), giugno 2012, MinervaWeb, <http://www.senato.it/3182? newsletter_item=1483\&newsletter_ numero=141>, 2012 ( 8 de mayo de 2017). 
discurso es bastante más completo y, al mismo tiempo, complejo. La segunda sección de la segunda parte de la «Filosofia della pratica» es el lugar que el abrucés elige para su consideración del principio ético ${ }^{39}$. Croce reivindica la formalidad del principio ético, con la consecuente imposibilidad de definir lo universal sobre la base de contenidos contingentes. Para él, la ética tiene que conservarse como categoría formal sin caer en un formalismo carente de contenido, ya que la vida moral busca la forma llena, no vacía, una forma en sentido filosófico y universal que, en el fondo, es contenido ${ }^{40}$ :

«... l'Etica formale, genuinamente formale, quella che noi accettiamo e propugniamo, non vuol essere formalistica, cioé malamente materiale ed effettivamente utilitaria; e sará anzi tutt'insieme materiale, nel significato alto della parola, perché intende dare non la mera condizione lógica del principio etico, ma questo principio etico stesso, definendo che cosa sia nella sua particolaritá e concretezza la volizione morale» ${ }^{41}$.

Es posible que esta crítica hacia el formalismo ético kantiano le sirva a Croce para sostener nuevamente la dinámica del «doble grado» de la actividad espiritual. Esto significa que la volición práctico-individual debe estar presidida por la dimensión universal del espíritu, dentro de una realidad histórica que, en sus hechos concretos, encuentra dinámicas de trasparencia y, al mismo tiempo, de misterio. Y es este el punto crucial de la consideración del principio ético en Croce, en el cual la moral laica abraza al misterio, o sea a las verdades de las sentencias religiosas y cristianas $^{42}$.

Aunque sea posible justificar el anti-moralismo en cuanto polémico hacia la hipocresía moral, o a favor de la moralidad efectiva; lo cierto es que el filósofo italiano reconoce que el auténtico oficio ético se observa en la ética religiosa y cristiana, aquella ética del amor y de la búsqueda ansiosa de la presencia divina. No existe verdad ética -afirma Croce- que no se pueda expresar con

39 Croce, B., Filosofia della pratica..., cit., con peculiar referencia a las pp. 279-303.

40 Ibid., pp. 287-288.

41 «La ética formal, genuinamente formal, la que nosotros aceptamos y propugnamos, no quiere ser formalistica, o sea malamente material y efectivamente utilitaria; quiere ser material en el sentido más alto de la palabra, ya que no pretende dar la mera condición lógica del principio ético, sino el principio ético mismo, definiendo lo que es la volición moral en su peculiaridad y concreción». Cfr. ibid., p. 288 (la traducción es nuestra).

42 En este sentido, seguramente más completo y complejo, ha sido interpretado por Cfr. MusTÈ, M., «Filosofia della pratica», cit., párrafo «Economia ed etica». 
las palabras, aprendidas desde pequeños, de la religión tradicional y que salen de nuestros labios como las más altas, las más idóneas, la más bellas. Palabras cargadas de mitología, de misterio y de contenido profundamente filosófico. Y es por esto -prosigue el abrucés- que el hombre religioso puede ver en el filósofo idealista (o sea, en él) un adversario, un enemigo mortal; pero, quizás, no sea consciente de que el filósofo, en cambio, verá en el hombre religioso su hermano menor ${ }^{43}$. De altísima tensión especulativa, como podemos comprobar, son estas últimas observaciones, puesto que las conexiones y los vínculos trazados por Croce entre el momento ético del espíritu y la ética religiosa resultan más que evidentes.

\section{HACÍA UNA NUEVA VISIÓN DEL DERECHO QUE FRENA LA UTILIDAD Y GARANTIZA LA MORALIDAD}

Podemos ver que, para Croce, la actividad económico-utilitaria acompaña las otras actividades y es participe de cualquier forma del espíritu, impregnando y condicionando toda la vida espiritual. No obstante, hemos comprobado que la filosofía crociana presenta importantes fundamentos teorético-morales, sobre todo, en las fases más avanzadas de su producción intelectual. Esto se debe a la atención que el filósofo italiano muestra hacia la totalidad de las expresiones de la vida y, en este sentido, se ha afirmado, con razón, que la filosofía de Croce adquiere un sentido trágico; claramente manifiesto por el paso de una posición de predominante economicismo a una madurez especulativa caracterizada por la eticización de su dialéctica. Un cambio pausado y una evolución intelectual lenta, que encuentran su ápice en los acontecimientos históricos relacionados con la Segunda Guerra Mundial ${ }^{44}$. La experiencia hitleriana, definida por Croce como un descenso al abismo ${ }^{45}$, y el sufrimiento «del»y «en» el mundo, le hacen percibir una degradación moral a la cual debe ponerse freno. Por esta razón, el abrucés advierte que el progreso histórico de la humanidad necesita la actuación de una racionalidad ética; el desfase entre ser y debe ser ha dificultado el pro-

43 Cfr. Croce, B., Filosofia della pratica..., cit., pp. 295-296.

44 Cfr. Troncarelli, B., «La categoría de la vitalitad en el último Croce», Zibaldone. Estudios italianos, n. ${ }^{\circ} 4$ (2014/2), pp. 33 у 35.

45 Croce, B., «L'ombra del mistero», en Il carattere della filosofia moderna, Laterza, Bari, 1941, p. 35 . 
greso y el proceso de crecimiento; la fractura entre realidad histórica e idea moral se ha consumido. Buena prueba de ello es la lucha entre las fuerzas vitales (del mal) y las fuerzas morales ${ }^{46}$.

La afirmación según la cual la historia nunca es justiciera, sino siempre justificadora, y la convicción de que el desarrollo histórico no es tránsito del mal al bien, ni vicisitud de bienes y males, sino tránsito del bien a lo mejor ${ }^{47}$, comienzan a encontrase en serias dificultades y precisan matizaciones o modificaciones. De acuerdo con esta tesis, en efecto, el juicio histórico solo podría exponer juicios positivos, algo que, a la luz de los hechos históricos (malvados, negativos, irracionales), no se puede aceptar. Croce se da cuenta de que la vitalidad, anteriormente identificada por él con la categoría espiritual de lo útil económico, puede atropellar al espíritu; pues se trata de una vitalidad concebida en términos de fuerza bruta, fuera de los límites racionales y causa de la degradación moral ${ }^{48}$. Las amargas experiencias de los totalitarismos y de la Guerra Mundial, como decíamos, llevaron al filósofo abrucés a interrogarse sobre la fuerza que impulsa a los hombres a realizar gestos tan terribles e inhumanos, una fuerza que es capaz de destruir la civilización. Esta fuerza Croce la denomina vitalidad, que se opone a la moralidad y a la libertad; aunque se trata de aquello que mueve la historia ya que ninguna acción humana, incluso noble, puede llevarse a cabo sin el impulso de satisfacción económica. Por esta razón, la vitalidad era, es y (paradógicamente) no es coincidente con lo útil. En consecuencia, destacábamos antes, la filosofía crociana adquiere un sentido especulativamente trágico, porque debe modificar el sistema espiritual; pero quiere y debe salvar su estructura.

En este estudio interesa señalar que la vitalidad -así entendida por Croce- acosa, o puede acosar, las experiencias humanas e históricas más notorias, como la política y el derecho. Se hace necesario, así, la oposición de la moralidad, única salvación y última posibilidad de recuperación armónica del sistema, a la vitalidad, entendida como conjunto de fuerzas del mal. Por una parte, Croce desea demostrar que existe una vitalidad puramente útil que no coincide con el mal, sino con un principio de racionalidad; por otra

46 Véase Croce, B., «Il progresso come stato d'animo e come concetto filosofico», en Filosofia e storiografia, Laterza, Bari, 1949, pp. 320 ss. Remitimos también a la brillante reconstrucción realizada por TRONCARELLI, B., «La categoría de la vitalitad...», cit., p. 37.

47 Cfr. Croce, B., Teoria e storia della storiografia, Laterza, Bari, 1976, p. 77 y 79.

48 Aquí seguimos utilizando las elaboraciones de Troncarelli, B., «La categoría de la vitalitad...», cit., pp. 36-37. 
parte, Croce admite que la vitalidad puede llegar a ser (y ha llegado a ser) esa fuerza bruta del mal contra la cual combate la moralidad. En el primer caso, la categoría espiritual de la vitalidad es posible encontrarla en lo útil $y$, por tanto, en el derecho; puesto que el derecho siempre es preferible al desorden salvaje de la anarquía y al ruinoso bellum omnium contra omnes ${ }^{49}$. En el segundo caso, al contrario, el italiano pretende manifestar que la vitalidad no siempre, ni necesariamente, es derecho o forma económica; más aún, cuando la vitalidad aparece como fuerza del mal, hasta el punto de generar una bipolaridad dialéctica entre lo negativo de la vitalidad y lo positivo de otras formas espirituales ${ }^{50}$.

En «Forze vitali e forze morali. Economia, politica ed etica», Croce establece y concreta definitivamente los detalles de la mencionada bipolaridad dialéctica. Frente a las impetuosas fuerzas vitales, que derriban todo lo que se opone a la satisfacción de su afán voraz de expansión, alimentación, gozo y dominación; el triunfo de la moralidad necesita la mediación del derecho, única categoría capaz de enfrentarse a los impulsos vitales e individualistas. El derecho, entonces, permite la afirmación de un individual moralizado, adquiriendo un papel fundamental para que se afirme y se rescate la moralidad. El derecho es el instrumento que la moralidad debe utilizar para triunfar en la lucha contra las fuerzas vitales y meramente individuales ${ }^{51}$. Nosotros sostenemos que cuando Croce habla de moralidad es muy probable que se refiera -y así sería coherente con su concepto de Libertad, que analizaremos en los próximos párrafos- a una idea de moralidad entendida como conjunto de buenas tradiciones, costumbres y usos del pueblo, de la sociedad y de la humanidad. La moralidad, en efecto, equivale a la costumbre y al carácter de una comunidad; de modo que calificar y tutelar la moralidad de un pueblo, equivale a proteger la sinceridad íntima, la pureza de conciencia y los modos de vida jurídicos de ese pueblo ${ }^{52}$.

Es evidente, por tanto, que esta nueva visión del derecho deja de ser aquella concepción a-moral del derecho mismo, porque se presenta ahora una concepción antivitalista del mismo como garantía de moralidad. Una visión práctico-instrumental del mismo, que permite traducir la universalidad ética

\footnotetext{
49 Cfr. Croce, B., «L'Apologia del diavolo e il problema del male», en Discorsi di varia filosofia, vol. I, Bibliopolis, Napoli, 2011, p. 189.

50 Cfr. Troncarelli, B., «La categoría de la vitalitad...», cit., p. 39.

51 Remitimos a la edición de CROCE, B., en Il carattere della filosofia moderna, cit., p. 239.

52 En este sentido véase Terán, J. M., Filosofía del derecho, Porrúa, México, 1996, p. 53.
} 
en los individuos y en las instituciones ${ }^{53}$. ¿Y si la ley jurídica no responde a las instancias éticas de justicia? Croce, demostrando no ser partidario de un legalismo a-moral, llega a justificar la rebelión a la ley injusta. Además, como si no bastase ya, refiriéndose a la Alemania nazi, el abrucés llega a invocar categorías básicas del derecho natural; observando que la afirmación según la cual hay que provocar el mayor daño al enemigo, encuentra un límite moral en la exclusión del daño a lo que es sagrado tanto para el enemigo como para nosotros mismos, en nombre de aquella moralidad denominada ius gentium ${ }^{54}$. Parece, por tanto, que la diferencia entre derecho y moral se manifiesta como una mera diferencia entre dos formas de la práctica, dos momentos dialécticos del querer, que mutuamente se encuentran implicados entre abstracción y concreción; pero útiles para entender la compleja fenomenología jurídica. El derecho, así entendido, está colmado de necesidades éticas: nace en la ética; confluye en ella con la interpretación; está presente en la ejecución espontánea y coactiva; se desarrolla en la ética; y puede apartarse de ella mediante las variadas formas del ius vivens.

Por último, decíamos que la vitalidad, en el nuevo sentido negativo crociano, puede acosar aquellas experiencias humanas e históricas más notorias, como la política y el derecho. Sobre el derecho se ha dicho; pero al respecto de la política, en este artículo, solo queremos hacer referencia al llamamiento que Croce hace a las conciencias de los hombres políticos. En «Considerazioni sul problema morale dei nostri tempi», las advertencias del italiano son duras y directas. En el sistema comunista -según Croce- es posible encontrar la misma actitud del nacionalismo fascista y nazi, una actitud ciega, irracional, incapaz de respetar valores o leyes de cualquier tipo. El italiano llega a afirmar que tanto los nacionalistas como los comunistas, así como los reaccionarios y los revolucionarios, demuestran, con sus acciones, haber bebido de la misma fuente envenenada; ya que con ellos hemos podido asistir a la destrucción de

53 En estos términos lo ha visto claramente TronCARELLI, B., «La categoría de la vitalitad en el último Croce», cit., pp. 39-40. Sobre el derecho entendido como un instrumento del operador jurídico y al servicio de la sociedad, entre Natura Rerum y mero constructivismo axiológico, se ha pronunciado recientemente MEDINA MoRAles, D., «El arte del derecho. La ley como instrumento del operador jurídico», en Una filosofía del derecho en acción. Homenaje al profesor Andrés Ollero, Servicio de Publicaciones del Congreso de los Diputados, Universidad Rey Juan Carlos, Madrid, 2015, pp. 557-573.

54 Se nos permita aquí, y nuevamente, remitir a las pertinentes conclusiones de Barbara Troncarelli, quien realiza una lectura combinada de las inquietudes del «primer» y del «segundo» Croce. Cfr. ibid., p. 40. 
todo sentimiento de humanidad común ${ }^{55}$. Es por esto que, nuevamente, se hace necesaria esa lucha contra los medios y las dinámicas de aquella vitalidad, que ha dejado de ser una forma económica del espíritu y se ha trasformado en una fuerza irracional impulsada por metas meramente individualistas. La política, por tanto, debe reconducirse hacia sus fines más nobles y alejarse de las fuerzas oscuras de la vitalidad que, en las últimas décadas, han demostrado su cara más cruel.

\section{LA POLÉMICA RELACIÓN ENTRE LIBERTAD Y JUSTICIA}

Desde la antigüedad, pensadores de todos los tiempos y lugares han querido acceder a la idea o al concepto de Justicia. Benedetto Croce, como es de suponer, no falta a esta cita (indispensable para todo gran intelectual) y comienza a tratar la temática rechazando, en primer lugar, el emparejamiento que se suele llevar a cabo entre los conceptos de Justicia y de Libertad ${ }^{56}$. Su preocupación consiste en descubrir el verdadero contenido de la palabra libertad y de la palabra justicia para, después, comprobarlos exactos términos de su eventual relación. Libertad, para el italiano, es la espiritualidad misma del hombre, su actividad, su realidad; es la esencia misma del hombre y este la posee en su calidad de hombre. Por esta razón -sostiene el autor-, la libertad no se puede conceder, porque al hombre no se le puede conceder algo que ya tiene de por sí. Del mismo modo, y si no se le puede conceder, tampoco se le puede quitar. En este sentido, los opresores de la libertad han podido apagar hombres, han prohibido acciones, han obligado a callar o a mentir; pero no han podido quitar a la humanidad su libertad, esto es, el tejido de su vida ${ }^{57}$.

$\mathrm{Si}$ queremos invocar el termino Libertad, por tanto, tendremos que hacerlo con la única y sola posible referencia al deber moral de favorecer y promover la vida de la humanidad, relegando en la esfera negativa cualquier acción que pueda menospreciarla. La Libertad, así, coincide con un principio de moralidad, el cual abarca todo tipo de deber moral y es todo lo que moral-

55 Cfr. Croce, B., «Considerazioni sul problema morale dei nostri tempi», en Scritti e discorsi politici (1943-1947), vol. II, Laterza, Bari, 1973, pp. 156 y 157.

56 Como si se tratara de dos nueces a poner sobre la misma mesa. Cfr. Croce, B., «Revisione filosofica dei concetti di 'Libertà' e 'Giustizia'», La Critica. Rivista di Letteratura, Storia e Filosofia, 41 (1943), p. 276.

57 Ibid., pp. 276 y 277. 
mente se hace y se debe hacer. Este principio encuentra su fuerza en la vida de la humanidad, por ello, Croce no tolera que la Justicia pueda entenderse como un factor de corrección (positivo o negativo) de la Libertad; porque ésta es un concepto espiritual y real que vive siempre y en todos los casos. Además, la Justicia ha sido entendida e interpretada según los contextos de referencia, no siendo por tanto capaz de acompañar a una categoría espiritual (Libertad) que muestra su moralidad humana en todo tiempo y lugar. ¿Cuáles son, para el abrucés, esos sentidos del termino Justicia? Fundamentalmente cuatro: la idea de bien moral o del hombre justo; la concepción asociada al derecho o a lo justo legal; la justicia como virtud; la justicia como igualdad.

El primero de estos significados reduce la palabra Justicia al bien moral o a los modos en que el hombre moral resiste a las pasiones, actuando como hombre justo. Una manera pobre de entender la Justicia, según Croce, pues finalmente acaba por afirmarse un concepto que presenta los mismos contenidos materiales (deberes morales) del concepto de Libertad. El segundo significado, en cambio, adquiere en la opinión crociana una mayor importancia, ya que se trata de la referencia al orden jurídico y legal que celebra la Justicia como fundamento de toda sociedad humana. En cualquier caso, la Justicia así entendida (orden, legalidad, estado, derecho) sigue siendo el presupuesto y la condición de la vida moral o de la libertad. Efectivamente, Croce nos recuerda que lo justo no puede reducirse a la mera obediencia de la ley, en la medida en que en esta concepción se concede poco espacio a la conciencia moral que, en cambio, y por ejemplo, obtuvo su primacía con el cristianismo. El tercer significado -advierte el abrucés- es posible encontrarlo en los libros de filosofía, ya que se hace del término Justicia una virtud o una clase entre las demás clases de virtudes, acudiendo así a los siguientes términos: justicia, equidad, benevolencia, amistad, prudencia, etc. Esta concepción de la Justicia, sin perjuicio de la elegancia dialéctica que puede llegar a alcanzar y debido a las diferentes notas y graduaciones observables o demostrables, nos enseña, en opinión del autor, la vertiente empírica y no estrictamente filosófica del principio de Justicia. El cuarto y último significado del término Justicia es, según Croce, el menos verdadero y, al mismo tiempo, el que más consecuencias produce. Veamos por qué.

Desde el punto de vista utilitarista y material, la Justicia entendida como exigencia de igualdad entre los hombres tiene, en la opinión del italiano, dos posibles significados: el primero consiste en la instauración de condiciones de vida económica iguales para todos los miembros de una sociedad con el fin de proporcionar a todos ellos el mismo bienestar; el segundo consiste en la abolición de las 
jerarquías sociales, tratando a los hombres como iguales en sus capacidades y en su participación en la obra social. En el primer caso, según Croce, no es posible concebir con exactitud cuáles sean las «mismas o iguales condiciones»y, menos aún, el «mismo bienestar». Esto se debe a que los hombres de la sociedad viven condiciones diferentes y son muy diferentes los sentimientos y las necesidades que cada uno querrá o podrá satisfacer. En consecuencia, no se puede pretender otorgar a todos el mismo bienestar, ni conceder iguales medios de satisfacción de intereses. En el segundo caso, de acuerdo con Croce, el resultado es de pura lógica, pues la diversidad de individualidades, necesidades, sentimientos, aptitudes y capacidades produce la inevitable jerarquía social. En este sentido, todos los individuos, en sus relaciones, serán supraordinados y/o subordinados en la vida social. Por todas estas razones, sostiene el filósofo italiano, la Justicia como exigencia de igualdad es una absurda ficción matemática de la realidad, porque la vida misma es anti-matemática. A mayor razón, dicha ficción será causa de malos sentimientos y de envidias hacia todo tipo de superioridad, ya sea la del afortunado o la del ingenioso y virtuoso hombre bueno que, en su propio oficio, se muestra superior y modesto al mismo tiempo ${ }^{58}$.

A juicio de Croce, la Revolución francesa, que se produjo en nombre de la igualdad, no solamente tenía un fondo de ficción matemática, sino también la intención de abolir las viejas condiciones sociales y económicas, así como las antiguas y artificiales jerarquías. Pues bien, la radical negación de las condiciones históricas, acompañada por el error lógico de la aplicación de la matemática a la vida en sociedad, representa -según el italiano- la base del error cometido por el jacobinismo y que se agitó en la falsa expectación de un resultado que, al final, se reveló ser justo contrario a lo deseado. De otro modo, en términos opuestos al citado abstracto racionalismo matemático, Croce nos recuerda que más inteligentes fueron los que aceptaron el pasado histórico con todas sus verdades, buenas y crueles, reconstruyendo y elaborando el ideal y la práctica del liberalismo en Inglaterra. No obstante, el error, en este último caso, consiste en haber ignorado la ley del mal y de la anti-liberalidad siempre presente en el pecho del hombre y en toda forma de vida social e histórica. La ética de la libertad suele encontrar delante de sí el obstáculo del eudemonismo con sus ideales de nivel más bajo, que se concretan en el placer, en el ocio o en la felicidad a conseguir necesariamente; aunque sea al caro precio de entregar la sociedad humana a un único pastor (Croce se refiere a las teocracias y a los regímenes dictatoriales) o

58 Ibid., pp. 278 у 279. 
dando lugar a una dinámica de convivencia que pueda satisfacer la más fútiles necesidades, mediante la ficticia voluntad común de todos los individuos (esta vez el autor se refiere a las democracias absolutas, socialismos y comunismos) ${ }^{59}$.

Por tanto, el autor admite que, de un modo u otro, es inevitable que a la idea de Libertad acabe por aparejarse o sobreponerse la de Justicia, incluso, como sinónimo. Pero esto, según el italiano, es ofensivo desde el punto de vista doctrinal y filosófico, en tanto que igualar los dos conceptos, las dos ideas o los dos valores, equivale a intentar evitar un delicado problema moral poco deseable, efectivamente, para los que quieren vivir sin pensar demasiado. Más aún, desde el punto de vista político, utilizar los dos términos como sinónimos equivale a justificar y a criticar los comportamientos de una u otra parte, liberal, socialista o comunista, permitiendo así el juego y las dinámicas del corrumpere et corrumpi. La ficticia combinación de ambos principios, que según Croce encontramos siempre en los programas políticos, debería ser rectificada. Para ello el autor hace un llamamiento a los jóvenes, quienes no deben dejarse engañar mediante pasionales invocaciones a la Libertad o falsas oratorias sacralizadas con el nombre de la Justicia. Detrás de estas invocaciones y elegantes discursos, siempre encontraremos las dificultades, los sufrimientos, las rebeliones, los esfuerzos y las esperanzas de los pueblos divididos en clases y grupos (algo, repetimos, realmente inevitable). Para ejercer el correcto y debido oficio, que radica en la elevación moral de la civilización y en la búsqueda de soluciones capaces de promover la auténtica y espiritual Libertad, deberemos ser valientes. Por esta razón, concluye Croce, el hombre de pensamiento puede llegar hasta un cierto punto, porque luego tendrá que entrar en juego el hombre de acción, quien será verdaderamente tal, si demuestra ser conservador y revolucionario al mismo tiempo ${ }^{60}$.

10. BREVES REFERENCIAS AL PROBLEMA RELIGIOSO: POR QUÉ NO PODEMOS NO DECIRNOS CRISTIANOS

Tradición histórica, por una parte, y progreso de la humanidad, por otra. Todo a favor de la lógica espiritual de la Libertad y sin caer en trampas dogmáticas, que tienen el único objetivo de rebajar el valor de la causa histórica

59 Ibid., pp. 280 y 281.

60 Ibid., pp. 282-284. 
del hombre en sociedad. Son estos los últimos y definitivos polos especulativos de Croce, quien en 1942 publica «Perché non possiamo non dirci cristiani», un breve ensayo en el cual el filósofo denuncia la hipocresía de quien no se manifiesta y reconoce como cristiano, siendo tal denominación el resultado de la simple observación de la verdad histórica. Enumera las causas de la revolución cristiana, que el abrucés define como la más grande que la humanidad haya podido conocer y realizar, llevada a cabo, fundamentalmente, en el interior y en el centro del alma y de la conciencia moral del hombre, para dotarlo de una nueva virtud, de una nueva cualidad espiritual. La historia del hombre europeo se dotó pronto del cristianismo y, según Croce, la conciencia moral del hombre se dotó de nuevas virtudes, con más confianza y más felicidad, con el sentido del pecado siempre presente y, al mismo tiempo, con el auto-dominio de una fuerza capaz de oponerse al pecado, para resistirle y para encontrar en la humildad su exaltación y en la servidumbre a Jesús la alegría ${ }^{61}$.

La historia del pensamiento jurídico y político demuestra que ya a partir de la antigüedad clásica se comienza a teorizar la existencia de un cierto núcleo de atribuciones e inherencias a los individuos; en aquel caso, sin embargo, se hablaba de un derecho natural, basado en la naturaleza de las cosas, que no sancionaba aun la esfera totalmente autónoma del individuo, ya que éste, antes de ser hombre, era ciudadano, soldado o magistrado. Se podría afirmar, entonces, que se llega a la consideración íntima y profunda del individuo y de sus atribuciones; pero sólo en sentido objetivo, en cuanto miembro del ente político y sólo dentro de éste. Sin embargo, según nuestro autor, hará falta esperar al cristianismo para asistir a una madura y fecunda concepción del individuo entendido como sujeto con dignidad y valor propio, independientemente del ente político de referencia: la consideración del hombre en cuanto tal, es cosa de la revolución cristiana. He aquí que se pone de relieve el problema de la subjetividad moral o de la dignidad moral del hombre en su calidad de persona, en la medida en que el hombre será ciudadano sin dejar de ser hombre, y trabajador sin dejar de ser hombre y ciudadano.

Resulta evidente que el germen de la historia moderna del hombre europeo reside en la intuición cristiana de la vida, intuición decisiva ya que determina no sólo el individuo sino también la persona. El progreso histórico de las manifestaciones humanas (la política y la jurídica) participa de un proceso que mantiene como centro de gravedad a la intuición cristiana de la vida. Una

61 Croce, B., Perché non possiamo non dirci «cristiani», Laterza, Bari, 1943, pp. 8 ss. 
concepción justificable por el refugio que Croce encuentra en una visión espiritualista de carácter cristiano, sin superar del todo sus más rígidas instancias idealistas e inmanentistas. Ha sido observado, con razón, que el descubrimiento del sufrimiento sustituye el juvenil descubrimiento de lo útil. De aquí el carácter religioso de las últimas reflexiones crocianas y, al mismo tiempo, su gran lección. La religiosidad cristiana, por una parte, y la racionalidad éticopolítica, por otra, son los caminos hacia la salvación; o sea, hacia el triunfo de los valores de la civilización y del curso histórico sobre la destrucción y el nihilismo causados por las dramáticas fuerzas de la vitalidad ${ }^{62}$. La luz resplandeciente de la obra cristiana reside en aquella conciencia moral que se activó, exultó y trabajó de manera férvida y esperanzadora. El hombre no puede no decirse cristiano, ya que el afecto de su Creador fue afecto de amor, de un amor hacia todos los hombres sin distinción de gentes y de clases, de libres y de esclavos, hacia todas las criaturas, hacia el mundo que es obra de Dios y un Dios que es Dios de amor, que desciende hacia el hombre y en el cual todos residimos, vivimos y nos movemos ${ }^{63}$.

Estamos hablando de sentimientos realmente vividos y no meramente pensados; posiblemente, verdades olvidadas y de las que, probablemente, hoy, nos avergonzamos. Croce nos pregunta si la humanidad podrá conocer otra revelación y religión, parecida o mayor a la que Hegel definía religión absoluta. Lo cierto es que siempre trabajamos para componer los duros contrastes entre inmanencia y trascendencia, entre moral de la conciencia y moral del imperativo y de las leyes, entre eticidad y utilidad, libertad y autoridad, lo celestial y lo terrenal. De una posible composición armónica de estos elementos dependerá nuestra tranquilidad interior o, en caso contrario, el sentimiento del combatiente y perpetuo trabajador al que nunca se le podrá quitar la materia esencial de su trabajo, esto es, la vida. El Dios cristiano sigue siendo el nuestro, asevera Croce. Semejante verdad no se puede eliminar de la vida espiritual del hombre, porque el proceso de búsqueda de la fe y, luego, su conquista, tendrá consecuencias prácticas en el mundo de las acciones. Negar tal verdad, al más puro estilo racionalista, o cerrarle las puertas de la dialéctica espiritual, equivale a la eutanasia de la verdad misma del hombre en la historia $\mathrm{y}$ en la sociedad ${ }^{64}$.

62 Nos referimos a Troncarelli, B., «La categoría de la vitalitad...», cit., pp. 49 y 45.

63 Croce, B., Perché non possiamo non dirci «cristiani», cit., pp. 8 y 9.

64 Ibid., pp. 24 y 13. 


\section{EPÍlogo}

Afirmar una rotunda «negación» crociana de la Filosofía del Derecho, así como su «reducción» a filosofía de la economía, en realidad, equivale a celar una perspectiva dialéctica evolutiva mucho más compleja y completa. En este trabajo hemos podido comprobar la existencia de dos etapas fundamentales en la evolución especulativa de Benedetto Croce; en todo caso, marcadas por un sistema dialéctico inmutado en su estructura. Queríamos saber si este filósofo italiano consiguió superar esa concepción que lo hizo tan famoso. A estas alturas, y a la luz de todas las anteriores consideraciones, podríamos afirmar que nunca la superó y que, al mismo tiempo, siempre la había superado. El derecho, para él, es básicamente una actividad útil y, al mismo tiempo, ínsita de valor. Es un conjunto de herramientas -escribíamos- que, desde una perspectiva económica, sirve para que los hombres puedan satisfacer sus necesidades y que, desde una perspectiva ética, sirve a la moral para que esta pueda reivindicar sus contenidos más básicos. Una categoría, por tanto, híbrida, que se ubica entre lo individual y lo universal (en la esfera práctico-volitiva de la dialéctica espiritual) y que participa de dos momentos distintos (no opuestos).

Si para Hegel la contradicción es «antítesis», para Croce la contradicción es un aspecto «distinto» de la realidad espiritual a tener siempre en consideración. Por esta razón, el abrucés proclama la existencia de cuatro momentos distintos: lo bello, lo verdadero, lo útil y lo ético. Dentro de cada uno de ellos podrán producirse dinámicas de oposición y entre ellos se establece una dialéctica de «doble grado» y de participación necesaria de lo individual en lo universal. Por esta razón, podrá existir una intuición sin concepto; pero no un concepto sin intuición. Del mismo modo, podrán realizarse acciones útiles y a-morales, pero no acciones éticas que no sean útiles. El derecho se nos presenta, así, como ese tertium quid que Croce trata implícitamente en su dialéctica, puesto que se trata de una actividad correspondiente a la esfera práctica del espíritu y que se manifiesta abstracta y concreta al unísono. En el primer caso, bajo el mero formato de leyes (meras abstracciones, diría el autor); en el segundo caso, bajo el formato ejecutivo espontaneo y/o aplicativo forzoso del precepto abstracto (momento sub legem, según el italiano). En el primer momento se presentan instancias éticos-universales, en el segundo se hacen vivas las exigencias útiles-individuales.

Respecto a la categoría de lo útil, Croce establece que ésta es moralmente neutra, ni viciosa ni virtuosa en sí misma. Es más, aquella acción útil que pretenda ser, desde su nacimiento, moralmente buena puede representar una 
peligrosa contradicción. Lo útil es una categoría autónoma del espíritu, a la que hay que devolver -en la opinión crociana- un espacio independiente para evitar que se apodere de los oficios éticos. No se trata, por tanto, del utilitarismo cuantitativo de Bentham, ni de la vertiente cualitativa de J. S. Mill. El abrucés reivindica la formalidad del principio ético, ya que, para él, la ética tiene que conservarse formal sin caer en un formalismo carente de contenido, puesto que la vida moral busca la forma llena, no vacua. Una forma en sentido filosófico y universal que, en el fondo, es contenido. La dinámica del «doble grado» de la actividad espiritual le permite así reafirmar que la volición práctico-individual debe estar presidida por la dimensión universal del espíritu, dentro de una realidad histórica que, en sus hechos concretos, en su devenir, encuentra dinámicas de trasparencia y, también, de misterio. La solución propuesta por Croce no ha sido entendida en su profundidad por toda la comunidad intelectual; bien pudiera ser porque una parte de ella le acusa de utilitarista, aptitud que, en cambio, él no desea mantener y que, además, desea renovar, superándola. Su objetivo principal consistió en salvar y rescatar la justicia de una impotente abstracción (mera idealidad), liberándola al mismo tiempo de una excesiva y potente concreción (mera utilidad).

El hombre justo, lo justo legal, la justicia como virtud y la justicia como igualdad, representan -a juicio del autor- los sentidos que el termino Justicia puede asumir según el contexto de referencia. Esto querrá decir que ninguno de ellos podrá consumir el sentido completo de la Diosa Justicia, pudiendo solamente mostrarnos algunas de sus actuaciones concretas. En algunos casos, además, dichas manifestaciones presentan peculiaridades que cualquier pensador que quiera calificarse como tal -diría Croce- no debe ignorar. El hombre justo, por ejemplo, es el hombre consciente de sus deberes hacia la humanidad y que, como hombre moral, resiste a las pasiones. Una manera pobre de entender la Justicia, según Croce, ya que acaba por afirmarse un concepto que presenta los mismos contenidos materiales del concepto de libertad. Hemos visto que la Libertad, para el italiano, es la espiritualidad misma del hombre, la esencia misma del hombre. Si se quiere invocar el termino Libertad, justamente, habrá que hacerlo con la única y sola posible referencia al deber moral de favorecer y promover la vida de la humanidad. La Libertad, así entendida, coincide con un principio de moralidad, porque comprende en sí todo tipo de deber moral y es todo lo que moralmente se hace y se debe hacer, encontrando su fuerza en la vida de la humanidad.

La referencia al orden jurídico y legal, que celebra la Justicia como fundamento de toda sociedad humana, representa el presupuesto y la condición 
de la vida moral o de la Libertad. Seguramente parecerá contradictorio este sentido axiológico de la Justicia con respecto a lo que Croce mantenía en los primeros años de su actividad intelectual. Nos estamos refiriendo a la firme defensa de la pureza de la esfera jurídica, esto es, que la Justicia en el derecho no encontraba sus bases en un principio moral ni inmoral, sino a-moral. Un principio de pura conveniencia económica, en virtud del cual no permitía la participación de la conciencia moral ni del remordimiento. Esto se debe a que el autor quiso presentar la legalidad como el esquema lógico-normativo de las acciones posibles, es decir, como el momento abstracto en el curso del proceso práctico, capaz de asegurar una coherencia a la acción, adelantándola, organizándola y predisponiéndola; a priori, sin dejar espacio para la participación de instancias éticas. Un posicionamiento que, como se ha podido comprobar, sufre importantes modificaciones en la última fase de la especulación crociana, ya que la atención demostrada por el abrucés hacía la totalidad de expresiones de la vida y en un momento histórico bastante delicado y complejo, así como la percepción de la degradación moral, las manifestaciones del mal y la fractura entre realidad histórica e idea moral, representan la justificación del carácter religioso de las últimas reflexiones del autor. En este último sentido, Croce desea señalar que las verdades de las sentencias religiosas y cristianas, por una parte, y la racionalidad ético-política, por otra, representan los caminos a seguir hacia una posible salvación, o sea, hacia el triunfo de los valores de la civilización sobre la destrucción y el nihilismo. 